\title{
Response to Comments on "Correlation between Radiologic Sign of Lumbar Lordosis and Functional Status in Patients with Chronic Mechanical Low Back Pain”
}

\author{
Alireza Ashraf ${ }^{1}$, Siamak Farahangiz ${ }^{2}$, Bita Pakniat Jahromi ${ }^{1,3}$, \\ Nazanin Setayeshpour ${ }^{1}$, Mahshid Naseri ${ }^{1}$, Ali Nasseri ${ }^{2}$ \\ ${ }^{I}$ Department of Physical Medicine and Rehabilitation, Shiraz Burn Research Center, Shiraz University of Medical Sciences, Shiraz, Iran \\ ${ }^{2}$ Department of Radiology, Shiraz University of Medical Sciences, Shiraz, Iran \\ ${ }^{3}$ Shiraz Geriatric Research Center, Shiraz University of Medical Sciences, Shiraz, Iran
}

Dear Editor,

We appreciate the interest in our work and for the opportunity to focus on detailed aspects of chronic mechanical low back pain. The reader attempted to emphasize the importance of pelvic incidence as a predictive factor for chronic low back pain. We should mention that concordant with this valuable comment there are several studies considering sagittal imbalance as a potential contributing factor for developing low back pain [1-3]. Pelvic incidence, a pelvic anatomic parameter that is specific and constant for each person determines the size of lumbar lordosis. Changes in this parameter either through relation with back muscle degeneration or other spine conditions might play a role in chronic mechanical low back pain [2-4].

The main focus of our study was lumbar lordosis and its effect on functional status measured by Oswestry disability index (ODI) that is not a simple pain score. Ac- cording to this index, no significant correlation between the degree of lumbar lordosis and the score of functional disability was found [5]. Also, in a recent study using ODI, osteoarthritis of the facet joints as specific locations of degenerative changes to the lumbar spine, was not definitely correlated with ODI scores [6]. On the other hand, 2 studies investigating the relationship between spinopelvic parameters and clinical symptoms of severe isthmic spondylolisthesis used ODI and found a significant correlation between degree of lumbar lordosis and the Oswestry score. However, there was no correlation between pelvic incidence and the Oswestry score $[7,8]$.

Disability is the main consequence of low back pain that should be prevented or treated once occurred. Thus, for more clarification we suggest randomized trials to evaluate possible relationships between the various spinopelvic alignment parameters such as pelvic incidence and the level of functional disability in patients with chronic mechanical low back pain.

Received Jan 2, 2015; Accepted Jan 3, 2015

Corresponding author: Mahshid Naseri

Department of Physical Medicine and Rehabilitation, Shahid Faghihi Hospital, Karimkhan Zand street, Shiraz, 71348-44119, Iran

Tel: +98-07-1123-1904, Fax: +98-07-1123-1904, E-mail: naseri_m@sums.ac.ir 


\section{Conflict of Interest}

No potential conflict of interest relevant to this article was reported.

\section{References}

1. Rigoard P, Blond S, David R, Mertens P. Pathophysiological characterisation of back pain generators in failed back surgery syndrome (part B). Neurochirurgie 2014 Nov 20 [Epub]. http://dx.doi.org/10.1016/j. neuchi.2014.10.104.

2. Vialle R, Ilharreborde B, Dauzac C, Lenoir T, Rillardon $\mathrm{L}$, Guigui P. Is there a sagittal imbalance of the spine in isthmic spondylolisthesis? A correlation study. Eur Spine J 2007;16:1641-9.

3. Labelle H, Roussouly P, Berthonnaud E, et al. Spondylolisthesis, pelvic incidence, and spinopelvic balance: a correlation study. Spine (Phila Pa 1976) 2004; 29:2049-54.

4. Nam WD, Chang BS, Lee CK, Cho JH. Clinical and radiological predictive factors to be related with the degree of lumbar back muscle degeneration: difference by gender. Clin Orthop Surg 2014;6:318-23 .

5. Ashraf A, Farahangiz S, Pakniat Jahromi B, Setayeshpour N, Naseri M, Nasseri A. Correlation between radiologic sign of lumbar lordosis and functional status in patients with chronic mechanical low back pain. Asian Spine J 2014;8:565-70.

6. Maataoui A, Vogl TJ, Middendorp M, Kafchitsas K, Khan MF. Association between facet joint osteoarthritis and the Oswestry Disability Index. World J Radiol 2014;6:881-5.

7. Wang Z, Wang B, Yin B, Liu W, Yang F, Lv G. The relationship between spinopelvic parameters and clinical symptoms of severe isthmic spondylolisthesis: a prospective study of 64 patients. Eur Spine J 2014;23:560-8.

8. Lu GH, Wang ZG, Wang B, et al. Relationship between variations of severe isthmic spondylolisthesis spino-pelvic parameters and clinical symptoms. Zhonghua Yi Xue Za Zhi 2013;93:1133-7. 